\title{
Aggregation and pH Responsive Behavior of Thioester Surfactants and Formation of Disulfide Linkages in Aqueous Solutions
}

\author{
Tsuyoshi Asakawa* , Yukina Takano, Akio Ohta and Hitoshi Asakawa \\ School of Chemistry, College of Science and Engineering, Kanazawa University, Kanazawa 920-1192, JAPAN
}

\begin{abstract}
H}$ responsive surfactants, $\left[\mathrm{C}_{12} \mathrm{H}_{25} \mathrm{~N}\left(\mathrm{CH}_{3}\right)_{2}\left(\mathrm{CH}_{2}\right)_{\mathrm{n}} \mathrm{SCOCH}_{3}\right] \mathrm{Br}\left(\mathrm{C}_{12} \mathrm{nSAc}, \mathrm{n}=4,11\right.$, 12), were prepared, and their properties in aqueous solution were examined. The critical micelle concentration (cmc) and critical vesicle concentration (cve) were determined based on changes in conductivity, as well as by fluorescence measurements, and light scattering methods. A significant increase in the light scattering intensities of the $\mathrm{C}_{12} \mathrm{nSAc}(\mathrm{n}=11,12)$ systems suggested that the growth of aggregates was accompanied by considerable counterion binding with increasing surfactant concentration. The diameter of $\mathrm{C}_{12} 11 \mathrm{SAc}$, recorded by the dynamic light scattering measurements, was about $9.6 \pm 1.0 \mathrm{~nm}$, which was slightly smaller than that for didodecyldimethylammonium bromide (DDAB) vesicles. The thioester group was easily hydrolyzed upon the addition of $\mathrm{NaOH}$, while it was hardly hydrolyzed with the addition of $\mathrm{HCl}$. The time course of alkaline hydrolysis was examined by the conductivity measurements and high-performance liquid chromatography analysis. $\left[\mathrm{C}_{12} \mathrm{H}_{25} \mathrm{~N}\left(\mathrm{CH}_{3}\right)_{2}\left(\mathrm{CH}_{2}\right)_{11} \mathrm{SS}\left(\mathrm{CH}_{2}\right)_{11} \mathrm{~N}\left(\mathrm{CH}_{3}\right)_{2} \mathrm{C}_{12} \mathrm{H}_{25}\right] 2 \mathrm{Br}\left(2 \mathrm{C}_{12} 11 \mathrm{SS}\right)$ was generated in the $\mathrm{C}_{12} 11 \mathrm{SAc}$ alkaline solution because of air oxidation. The $\mathrm{C}_{12} 11 \mathrm{SAc}$ alkaline solution gradually became an opaque blue color with increasing light scattering at $346 \mathrm{~nm}$, indicating the remarkable growth of vesicles. The chemical structure of $2 \mathrm{C}_{12} 11 \mathrm{SS}$ was consistent with that of a disulfide linked double tailed surfactant, similar to DDAB. The disulfide linkage between the double tailed surfactants will contribute to the stabilization and growth of vesicles.
\end{abstract}

Key words: double tailed thioester surfactant, critical vesicle concentration, disulfide linkage by hydrolysis and oxidation, vesicular growth

\section{INTRODUCTION}

Stimuli responsive surfactants have been developed to regulate the release of drugs from vesicles. The responsiveness of these surfactants to stimuli such as redox gradient, light, and $\mathrm{pH}$ have been used as a trigger for the release ${ }^{1-4)}$. Since the thioesters can be easily hydrolyzed in alkaline solution $^{5,6)}$, they are expected to the most appropriate candidates for $\mathrm{pH}$ responsive surfactants. The hydrolysis product, a thiol surfactant, is prone to oxidation to yield a disulfide linkage in aerated alkaline solution, which exposed to air without replacement by nitrogen $\operatorname{gas}^{7)}$. Therefore, monomeric thioester surfactants will be converted to disulfide linked surfactants by hydrolysis and oxidation processes. Cross-linking of surfactants has been recognized as a powerful approach for stabilizing micelles. The disulfide linkage can be cleaved to release the entrapped drugs. We have reported that the hydrophobic pyrene is released during the reduction of gemini micelles into monomeric thiol surfactants upon the addition of dithiothreitol(DTT), which is commonly used to cleave the disulfide bond into free thiols ${ }^{8}$. Moreover, the produced thiol surfactants return to the original disulfide-linked gemini form in aerated solution. Therefore, control of surfactant aggregation will lead to controlled release of the solubilized substances in the micelles.

Didodecyldimethylammonium bromide (DDAB) is a wellknown surfactant that aggregates into vesicles ${ }^{9,10)}$. However, DDAB has no stimuli responsive groups in its amphiphilic structure. If vesicles are used as drug carriers, controlled release of the solubilizates is desired. Stimuli responsive surfactants can be designed to enable the release of the loaded solubilizates from a vesicle.

In this study, we focused on $\mathrm{pH}$ responsive vesicle formation of thioester surfactants. The thioacetate groups at the

\footnotetext{
*Correspondence to: Tsuyoshi Asakawa School of Chemistry, College of Science and Engineering, Kanazawa University, Kanazawa 920-1192, JAPAN

E-mail: asakawa@se.kanazawa-u.ac.jp

Accepted October 6, 2017 (received for review August 28, 2017)

Journal of Oleo Science ISSN 1345-8957 print / ISSN 1347-3352 online

http://www.jstage.jst.go.jp/browse/jos/ http://mc.manusriptcentral.com/jjocs
} 


\section{T. Asakawa, Y. Takano, A. Ohta et al.}

terminal part of the hydrophobic chain are hydrolyzed by equimolar $\mathrm{NaOH}$, leading to an increase in the hydrophobicity and elimination of the hydrophilic thioester moieties. The deprotected thiol groups will be slowly oxidized into disulfide bonds in alkaline solution, resulting in the generation of a hydrophobic disulfide-linked gemini surfactants. Hence, an increase in the hydrophobicity along with deprotection will aid the $\mathrm{pH}$ responsive growth of vesicles. We examined the aggregation behavior of thioester and disulfide-linked surfactants generated by hydrolysis and oxidation process. The conductivity, fluorescence probe and light scattering methods were utilized to evaluate not only critical micelle concentration (cmc) but also critical vesicle concentration (cvc). The conductivity measurements and high-performance liquid chromatography (HPLC) analysis were conducted to monitor the hydrolysis of the thioester. The dynamic light scattering method (DLS) was used to determine the diameters of the aggregates, which were compared with those of double tailed surfactants.

\section{EXPERIMENTAL PROCEDURES}

\subsection{Materials}

$\left[\mathrm{C}_{12} \mathrm{H}_{25} \mathrm{~N}\left(\mathrm{CH}_{3}\right)_{2}\left(\mathrm{CH}_{2}\right)_{\mathrm{n}} \mathrm{SCOCH}_{3}\right] \mathrm{Br}\left(\mathrm{C}_{12} \mathrm{nSAc}, \mathrm{n}=4,11\right)$ was prepared by refluxing $N, N$-dimethyldodecylamine (Tokyo Kasei Kogyo) and an equimolar amount of $S$ (4-bromobutyl) thioacetate or $S$-(11-bromoundecyl) thioacetate (Sigma-Aldrich) in acetonitrile for $6 \mathrm{~h}$. After the evaporation of acetonitrile, the products were washed with acetone and were purified by recrystallization from petroleum ether. $\left[\mathrm{C}_{12} \mathrm{H}_{25} \mathrm{~N}\left(\mathrm{CH}_{3}\right)_{2}\left(\mathrm{CH}_{2}\right)_{12} \mathrm{SCOCH}_{3}\right] \mathrm{Br}\left(\mathrm{C}_{12} 12 \mathrm{SAc}\right)$ was prepared by refluxing $N, N$-dimethyldodecylamine and an equimolar quantity of 1,12-dibromododecane (Tokyo Kasei Kogyo) in ethanol for $6 \mathrm{~h}$, followed by the reaction with an equimolar amount of potassium thioacetate in ethanol for $24 \mathrm{~h}$ with stirring, as shown in Scheme 1. After removal of the precipitated $\mathrm{KBr}$, the products were washed with acetone and were purified by recrystallization from petroleum ether. The $\mathrm{C}_{12} \mathrm{nSAc}$ systems were preserved under reduced pressure over $\mathrm{P}_{2} \mathrm{O}_{5}$. DDAB (Tokyo Kasei Kogyo) and dodecyltrimethylammonium bromide(DTAB, Tokyo Kasei Kogyo)were purified by recrystallization from acetone. 6-Methoxy- $N$ - (3-sulfopropyl) quinolinium (SPQ, Dojindo Labo.) and DTT (Wako Pure Chemical Industries, Ltd.) were used as received.

\subsection{Measurements}

Aqueous solutions of the surfactants were prepared by sonication for 5-10 min and then equilibrated for $24 \mathrm{~h}$ at $25^{\circ} \mathrm{C}$. The conductivities of the aqueous surfactant solutions were measured using a DS-52 (HORIBA) conductivity meter. The fluorescence spectra of $10^{-6} \mathrm{M}$ SPQ in surfactant solutions were measured in the range 340 - $500 \mathrm{~nm}$ under excitation at $346 \mathrm{~nm}$ using a Hitachi F-2700 spectrophotometer. The intensities of SPQ fluorescence at $443 \mathrm{~nm}$ were recorded as well as the intensity of light scattering at $346 \mathrm{~nm}$. DLS measurements were performed using an SZ-100 (HORIBA) system to determine the diameter of the aggregates. The produced surfactants were analyzed by HPLC, as reported previously ${ }^{11)}$. A TSKgel ODS-100V (TOSOH) column was used with a methanol/30 mM sodium 1-octanesulfonate (90:10) mixtures as the eluent. The elution of the surfactant was detected based on the absorption at $210 \mathrm{~nm}$ and electrical conductivity.

\section{RESULTS AND DISCUSSION}

3.1 Monolayer vesicle formation from thioester surfactants

The conductivity method was used to determine the cmc of the thioester surfactant in comparison with that of a conventional cationic surfactant. Figure 1 (a) shows the conductivity curves for aqueous solutions of DTAB and $\mathrm{C}_{12} 4 \mathrm{SAc}$ plotted against the surfactant concentration. The experimental data showed linear plots at concentrations below the cmc. The slope corresponding to $\mathrm{C}_{12} 4 \mathrm{SAc}$ monomer was identical to that of DTAB. The ratio of the slopes above and below the cmc, $\mathrm{S}_{2} / \mathrm{S}_{1}$, has been used as a measure of the degree of micellar ionization ${ }^{12)}$. The $\mathrm{S}_{2} / \mathrm{S}_{1}$ value for $\mathrm{C}_{12} 4 \mathrm{SAc}$ was similar to that of DTAB, suggesting the formation of typical micelles. The cmc of $6.3 \mathrm{mM}$ for $\mathrm{C}_{12} 4 \mathrm{SAc}$ was lower than $14.9 \mathrm{mM}$ of DTAB owing to the hydrophobicity of the four methylene groups in the second alkyl chain. Figure 1(b) shows the conductivity curves for aqueous solutions of DDAB, $\mathrm{C}_{12} 11 \mathrm{SAc}$ and $\mathrm{C}_{12} 12 \mathrm{SAc}$ plotted against the surfactant concentration. The slope for the conductivity curve gradually decreased with increasing surfactant concentration. The presence of two inflection points has been reported for double tailed surfactants ${ }^{13)}$. The $\mathrm{S}_{2} / \mathrm{S}_{1}$ value for DDAB was 0.51 above the cmc, suggesting the presence of smaller aggregates, but those decreased drastically to 0.07 with increasing surfactant concentration. The first inflection point corresponded to the cmc of 0.23

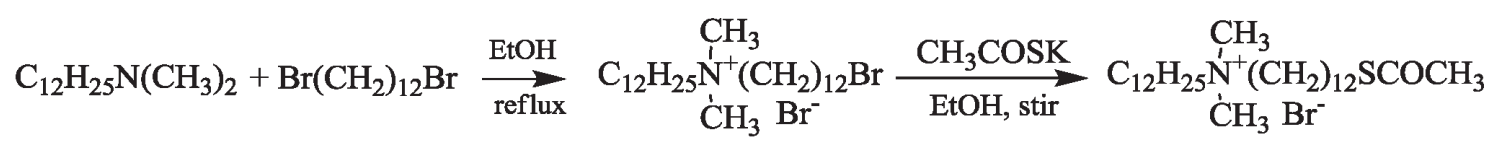

Scheme 1 Preparation of cationic surfactant containing a thioester group in the terminal of hydrophobic alkyl chain. 


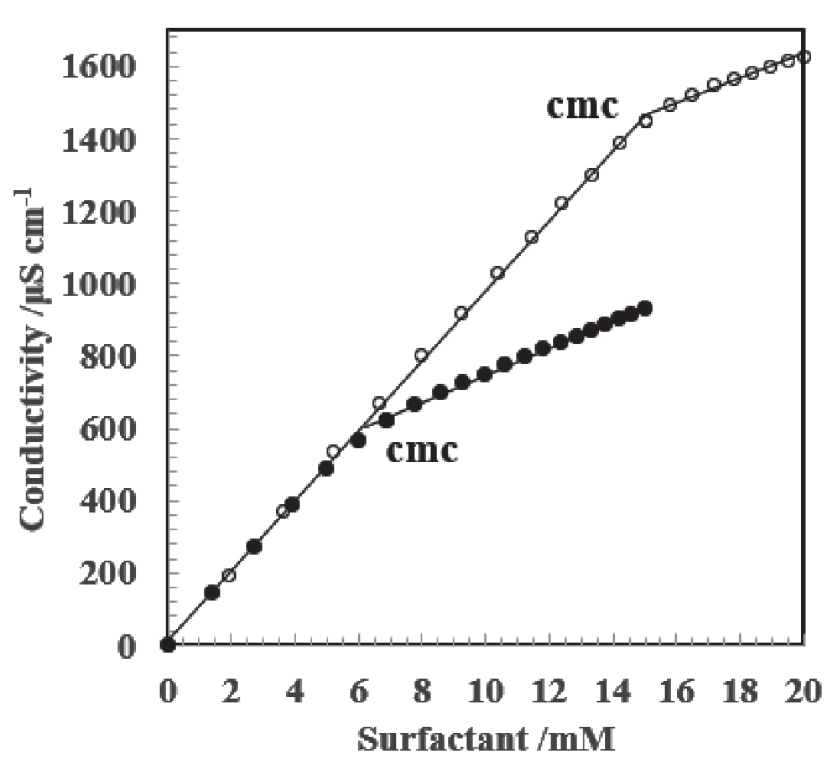

Fig. 1 (a) The conductivity curves for aqueous solutions of DTAB and $\mathrm{C}_{12} 4 \mathrm{SAc}$ against the surfactant concentration. (O) DTAB, $(\bigcirc) \mathrm{C}_{12} 4 \mathrm{SAc}$.

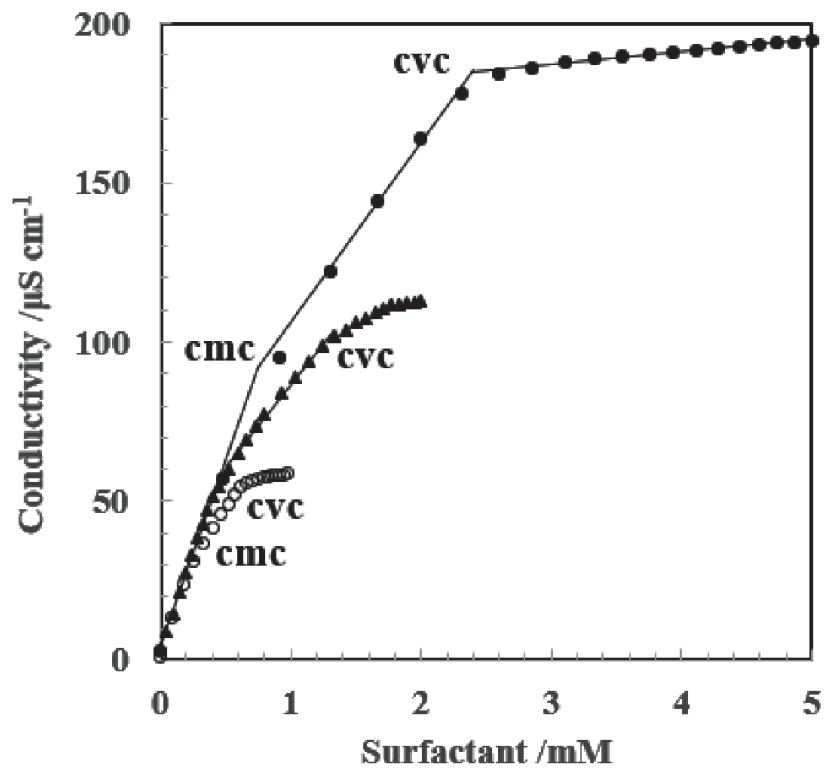

Fig. 1 (b) The conductivity curves for aqueous solutions of DDAB, $\mathrm{C}_{12} 11 \mathrm{SAc}$ and $\mathrm{C}_{12} 12 \mathrm{SAc}$ against the surfactant concentration. ( $\bigcirc)$ DDAB, $\mathrm{C}_{12} 11 \mathrm{SAc},(\boldsymbol{\Delta}) \mathrm{C}_{12} 12 \mathrm{SAc}$.

$\mathrm{mM}$, while the second inflection point corresponded to the cvc of $0.63 \mathrm{mM}$ for the DDAB vesicle with significant counterion binding. Both $\mathrm{C}_{12} 11 \mathrm{SAc}$ and $\mathrm{C}_{12} 12 \mathrm{SAc}$ systems showed similar trends in the conductivity curves, with the presence of two inflection points. The cmc of $\mathrm{C}_{12} 11 \mathrm{SAc}$ was about three times higher than that of $\mathrm{DDAB}$ owing to the presence of the polar thioester group, which could form hydrogen bonds with the adjacent water molecules. The second inflection point of $\mathrm{C}_{12} 11 \mathrm{SAc}$ was nearly four times higher than that of DDAB, whereas the slope of the conductivity curve was almost identical with that of DDAB, suggesting vesicle formation with significant counterion binding. The cmc of $\mathrm{C}_{12} 12 \mathrm{SAc}$ was about half of that for $\mathrm{C}_{12} 11 \mathrm{SAc}$ owing to the hydrophobicity of the methylene group. This suggested that the hydrophobic contribution of a methylene group in the second alkyl chain is fair agreement with that in the main alkyl chain.

Counterion binding relates to the formation of an aggregate composed of ionic surfactants, wherein electrostatic repulsion between the headgroups is alleviated. The degree of counterion binding to the micelles influences the size and shape of the aggregates. The degree of counterion binding has been determined by various experimental methods such as conductivity measurements, electromotive force measurements, and NMR experiments ${ }^{14-18)}$. The simple two-site model has been used to estimate the concentration of free ions in the aqueous bulk phase and the bound ions in the micellar phase. We have demonstrated that fluorescence quenching studies of SPQ allow for direct measurements of the concentration of halides dissociated from the surfactant ${ }^{19)}$. When quenching occurs by collision between SPQ probe and the halide ion quencher, the variation in the fluorescence intensity would be related to the concentration of quencher[Q] by the Stern-Volmer equation, $\mathrm{I}_{0} / \mathrm{I}=1+\mathrm{K}_{\mathrm{SV}}[\mathrm{Q}]$, where $\mathrm{I}_{0}$ and $\mathrm{I}$ are the fluorescence intensities in the absence and presence of the quencher, respectively, and $\mathrm{K}_{\mathrm{SV}}$ is the Stern-Volmer constant. Figure 2 (a) shows that the fluorescence of SPQ is quenched by bromide ions, with a linear Stern-Volmer relation below the cmc. The slope of plots, $\mathrm{K}_{\mathrm{SV}}=227 \mathrm{M}^{-1}$, was in fair agreement with $\mathrm{K}_{\mathrm{SV}}=223 \mathrm{M}^{-1}$ of $\mathrm{NaBr}$, indicating that the thioester groups hardly influence the SPQ fluorescence quenching. The Stern-Volmer plot revealed a distinct break at the cmc of $\mathrm{C}_{12} 4 \mathrm{SAc}$ owing to the binding of the bromide counterion to the micelles. The SPQ fluorescence was quenched by the free bromide ions dissociated from the surfactant. The degree of micellar ionization $\left(\alpha_{m}\right)$ for $\mathrm{C}_{12} 4 \mathrm{SAc}$ was 0.17 , which is similar to that of DTAB. Figure 2 (b) shows that the Stern-Volmer plots for the $\mathrm{C}_{12} 11 \mathrm{SAc}$ and $\mathrm{C}_{12} 12 \mathrm{SAc}$ systems. The second inflection points were in accord with those of conductivity measurements, corresponding to cvc. The degree of vesicular ionization $\left(\alpha_{\mathrm{v}}\right)$ for $\mathrm{C}_{12} 12 \mathrm{SAc}$ is significantly higher than that of $\mathrm{C}_{12} 11 \mathrm{SAc}$. This could be due to the differences in the length of the second alkyl chain, i.e., the length misfit associated with the main alkyl chain. The polar thioester group at the alkyl chain terminal for $\mathrm{C}_{12} 12 \mathrm{SAc}$ could be conveniently located around the surface of the aggregates, so that resulting in the counterion dissociated from $\mathrm{C}_{12} 12 \mathrm{SAc}$. The thioester group of the surfactant in the inner layer of the vesicles could protrude toward the outer layer. The vesicles formed from $\mathrm{C}_{12} 12 \mathrm{SAc}$ had an interdigitated structure that alleviated the electrostatic repulsion between the headgroups as 
shown in Scheme 2.

The vesicle formation in the case of DDAB has been verified by cryogenic transmission electron microscopy studies $^{9,10)}$. The cvc of DDAB can be determined conve-

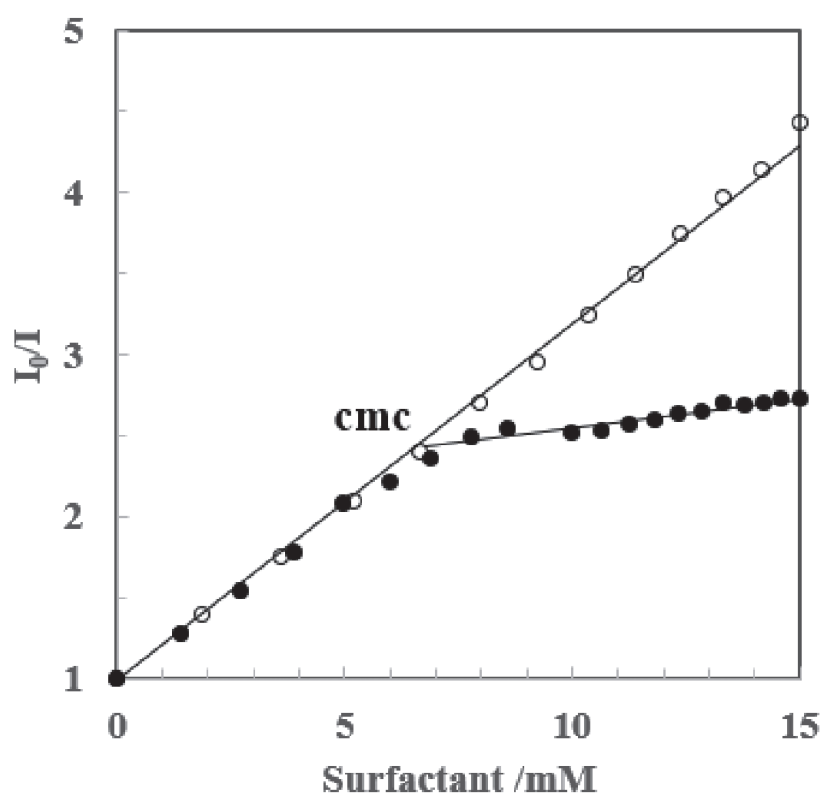

Fig. 2 (a) Stern-Volmer plots for quenching of SPQ fluorescence by bromide ion dissociated from surfactant aggregates. (O) DTAB, ( $\mathrm{C}_{12} 4 \mathrm{SAc}$. niently by the light scattering method ${ }^{13)}$. Figure 2 (c) shows the variations in the intensity of light scattering $\left(\mathrm{I}_{\mathrm{s}}\right)$ at 346 $\mathrm{nm}$. The $\mathrm{I}_{\mathrm{s}}$ values for the aqueous DTAB solutions are almost identical to that of water, whereas significant in-

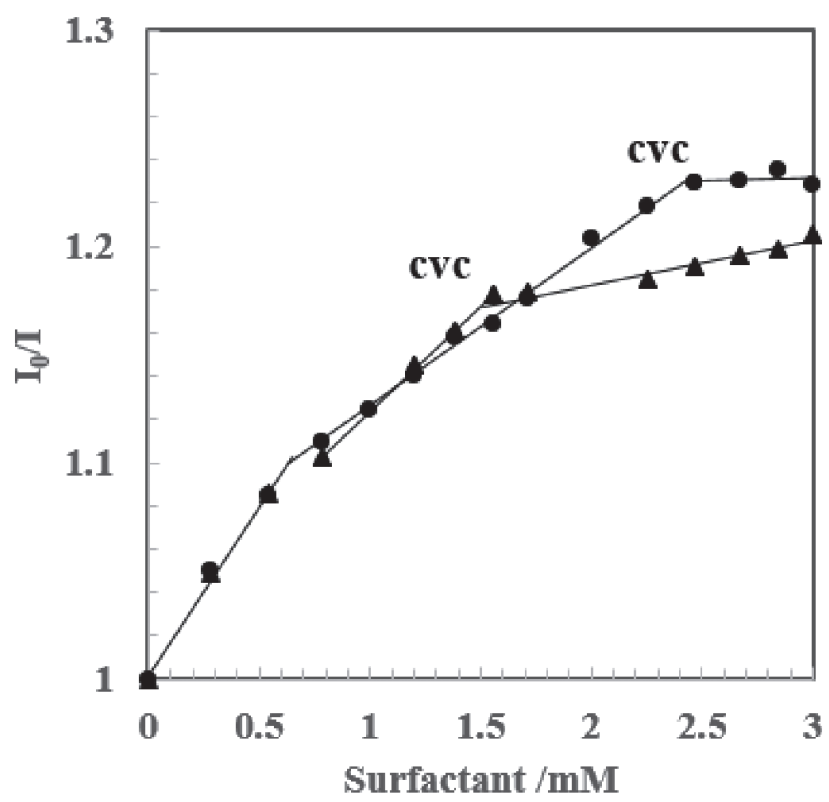

Fig. 2 (b) Stern-Volmer plots for quenching of SPQ fluorescence by bromide ion dissociated from surfactant aggregates. $(\mathbf{O}) \mathrm{C}_{12} 11 \mathrm{SAc},(\boldsymbol{\Delta})$ $\mathrm{C}_{12}$ 12SAc.

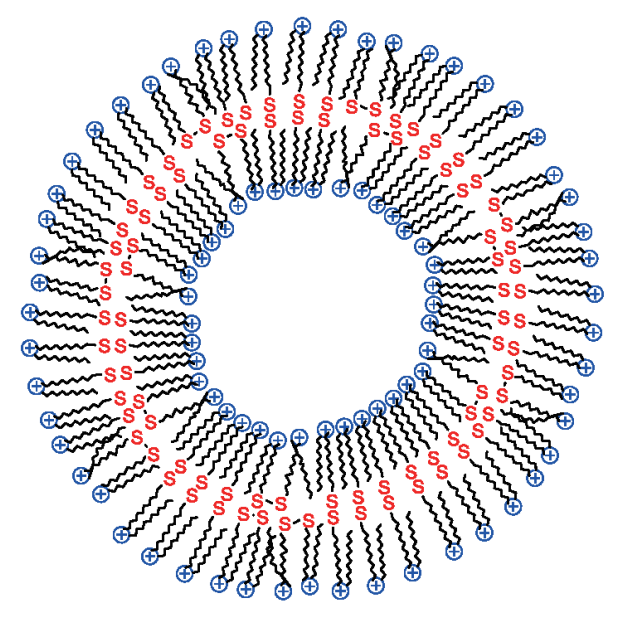

(xims s-s 2 mint

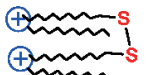

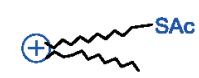

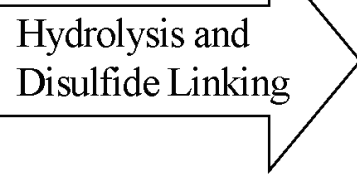

$$
\begin{gathered}
\stackrel{\mathrm{CH}_{3}}{\mathrm{H}_{3}} \mathrm{C}_{12} \mathrm{H}_{25}\left(\mathrm{CH}_{2}\right)_{12} \mathrm{SCOCH}_{3} \\
\stackrel{\dot{\mathrm{C}} \mathrm{H}_{3} \mathrm{Br}^{-}}{\mathrm{B}_{12}} \\
\mathrm{C}_{12} 12 \mathrm{SAc}
\end{gathered}
$$

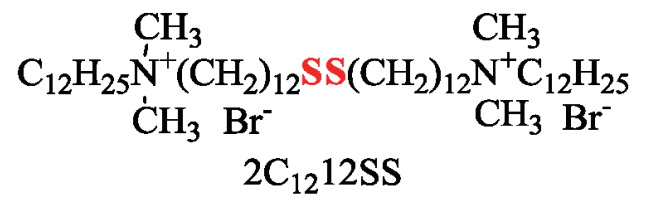

Scheme 2 The remarkable growth in $2 \mathrm{C}_{12} 12 \mathrm{SS}$ aggregates produced by the stimuli responsive thioester surfactants. 


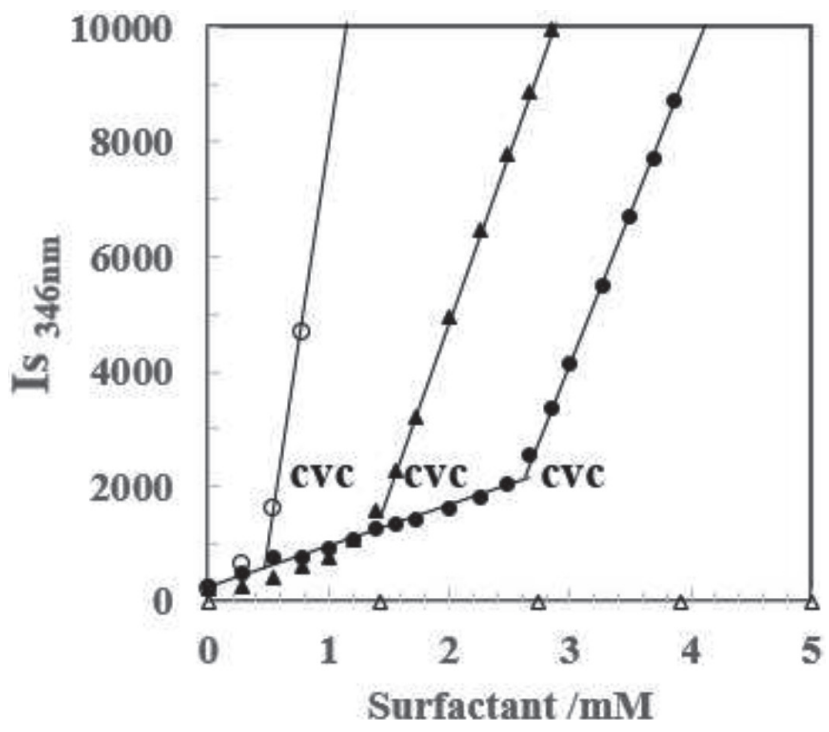

Fig. 2 (c) The variations in the intensity of light scattering at $346 \mathrm{~nm}$. ( $\bigcirc)$ DDAB, ( $\mathrm{C}_{12} 11 \mathrm{SAc},(\boldsymbol{\Delta})$ $\mathrm{C}_{12} 12 \mathrm{SAc},(\triangle) \mathrm{DTAB}$.

creases in $\mathrm{I}_{\mathrm{s}}$ are observed above $0.58 \mathrm{mM}$ of DDAB, which can be determined as the cvc. The opaque blue color of the $\mathrm{DDAB}$ solutions suggests vesicle formation. The cvc values for $\mathrm{C}_{12} 11 \mathrm{SAc}$ and $\mathrm{C}_{12} 12 \mathrm{SAc}$ are higher than that of DDAB, which is in fair agreement with the values determined by the conductivity method. The results of the conductivity and SPQ fluorescence probe methods are summarized in Table 1. DLS measurements have been conducted to estimate the hydrodynamic diameter of the aggregates ${ }^{20,21)}$. The average diameter of the DDAB vesicle is twice that of the $\mathrm{C}_{12} 11 \mathrm{SAc}$ and $\mathrm{C}_{12} 12 \mathrm{SAc}$ systems. We calculated the length of alkyl chain $\left(l_{\mathrm{H}} / \mathrm{nm}\right)$ with carbon number $\left(\mathrm{n}_{\mathrm{c}}\right)$ using the relation, $l_{\mathrm{H}}=0.15+0.126 \mathrm{n}_{\mathrm{c}}$, the length of the DDAB surfactant monomer is about $2 \mathrm{~nm}$, leading to a vesicle bilayer thickness of $4 \mathrm{~nm}$. The hydrodynamic diameter of DDAB, as determined by DLS measurements, is $20.7 \pm 6.7$ $\mathrm{nm}$, and it seems to be a reasonable vesicular size including the inner water phase. These results are in fair agreement with those in the previous reports ${ }^{12)}$. On the other hand, the results for pertaining to smaller hydrodynamic diameter of $\mathrm{C}_{12} 12 \mathrm{SAc}$ suggest that the thioester surfactants adopted an interdigitated packing in the vesicle bilayers. In other words, the thioester group might orient toward the polar water region rather than the hydrophobic region, as shown in Scheme 2.

\subsection{Growth of the monolayer vesicle to bilayer vesicle in alkaline solution}

We further examined the thioester hydrolysis of the $\mathrm{C}_{12} 11 \mathrm{SAc}$ system in aqueous solutions. The high reactivity of the thioester is partially due to the lack of the resonance stabilization mechanism in the ground state, i.e., the $3 p$ orbital of sulfur overlaps poorly with the $2 p$ orbital of the carbonyl. Hydrolysis of the alkyl thioester is performed via acid and base catalysis ${ }^{22)}$. Alkaline hydrolysis is an irreversible reaction that occurs due to the attack of the hydroxide ion on the electron-deficient carbonyl carbon. On the other hand, acid hydrolysis is a reversible reaction that occurs by the protonation of the carbonyl oxygen. Figure 3 shows the HPLC profiles recorded at $210 \mathrm{~nm}$ for the incubated $\mathrm{C}_{12} 11 \mathrm{SAc}$ systems. An aqueous solution of $10 \mathrm{mM} \mathrm{C} \mathrm{C}_{12} 11 \mathrm{SAc}$ is incubated at $40^{\circ} \mathrm{C}$ in the presence of $10 \mathrm{mM} \mathrm{HCl}$ or 10 $\mathrm{mM} \mathrm{NaOH}$. The elution of $\mathrm{C}_{12} 11 \mathrm{SAc}$ is detected at $2.7 \mathrm{~min}$. Despite incubation for $24 \mathrm{~h}$, the peak area for acidic $\mathrm{C}_{12} 11 \mathrm{SAc}$ system remains constant but is remarkably reduced for the alkaline $\mathrm{C}_{12} 11 \mathrm{SAc}$ system. The new elution peak at $11.1 \mathrm{~min}$ corresponds to the formation of the disulfide-linked surfactant, $2 \mathrm{C}_{12} 11 \mathrm{SS}$. The disulfide cleavage of $2 \mathrm{C}_{12} 11 \mathrm{SS}$ is confirmed by the addition of DTT. The produced thiol $\left(\mathrm{C}_{12} 11 \mathrm{SH}\right)$ is detected at $3.0 \mathrm{~min}$, which is somewhat longer than the elution time of $\mathrm{C}_{12} 11 \mathrm{SAc}$ owing to the elimination of the polar thioester group. The cationic $\mathrm{C}_{12}$ 11SAc aggregates accelerate the alkaline hydrolysis, probably owing to the concentration effect of the opposite charges for $\mathrm{OH}^{-}$, whereas such a behavior is considerably inhibited under acidic conditions. The hydrolysis product, $\mathrm{C}_{12} 11 \mathrm{SH}$, is prone to be oxidized to disulfide linkage in aerated alkaline solution. Consequently, $\mathrm{C}_{12} 11 \mathrm{SAc}$ produces to disulfide-linked surfactants, $2 \mathrm{C}_{12} 11 \mathrm{SS}$, by the hydrolysis and oxidation processes.

Table 1 Aqueous solution properties of cationic surfactants at $25^{\circ} \mathrm{C}$.

\begin{tabular}{|c|c|c|c|c|c|c|c|c|c|}
\hline \multirow[b]{2}{*}{ Surfactant } & \multicolumn{4}{|c|}{ Conductivity } & \multicolumn{4}{|c|}{ SPQ } & \multirow{2}{*}{$\begin{array}{c}\text { DLS } \\
\begin{array}{c}\text { Diameter } \\
/ \mathrm{nm}\end{array}\end{array}$} \\
\hline & $\begin{array}{l}\mathrm{cmc} \\
/ \mathrm{mM}\end{array}$ & $\mathrm{S}_{2} / \mathrm{S}_{1}$ & $\begin{array}{l}\mathrm{cvc} \\
/ \mathrm{mM}\end{array}$ & $\mathrm{S}_{3} / \mathrm{S}_{1}$ & $\begin{array}{l}\mathrm{cmc} \\
/ \mathrm{mM}\end{array}$ & $\alpha_{\mathrm{m}}$ & $\alpha_{v}$ & $\begin{array}{l}\mathrm{cvc}^{*} \\
/ \mathrm{mM}\end{array}$ & \\
\hline DTAB & 14.9 & 0.35 & - & - & 16.4 & 0.19 & - & - & - \\
\hline $\mathrm{C}_{12} 4 \mathrm{SAc}$ & 6.3 & 0.39 & - & - & 6.6 & 0.17 & - & - & - \\
\hline $\mathrm{C}_{12} 11 \mathrm{SAc}$ & 0.78 & 0.55 & 2.4 & 0.07 & 0.62 & 0.34 & 0.01 & 2.6 & $9.6 \pm 1.0$ \\
\hline $\mathrm{C}_{12} 12 \mathrm{SAc}$ & 0.45 & 0.45 & 1.3 & 0.14 & 0.42 & 0.46 & 0.10 & 1.4 & $7.5 \pm 3.5$ \\
\hline DDAB & 0.23 & 0.51 & 0.63 & 0.07 & - & - & - & 0.58 & $20.7 \pm 6.7$ \\
\hline
\end{tabular}

*cvc were determined by the abrupt increase in light scattering at $346 \mathrm{~nm}$. 


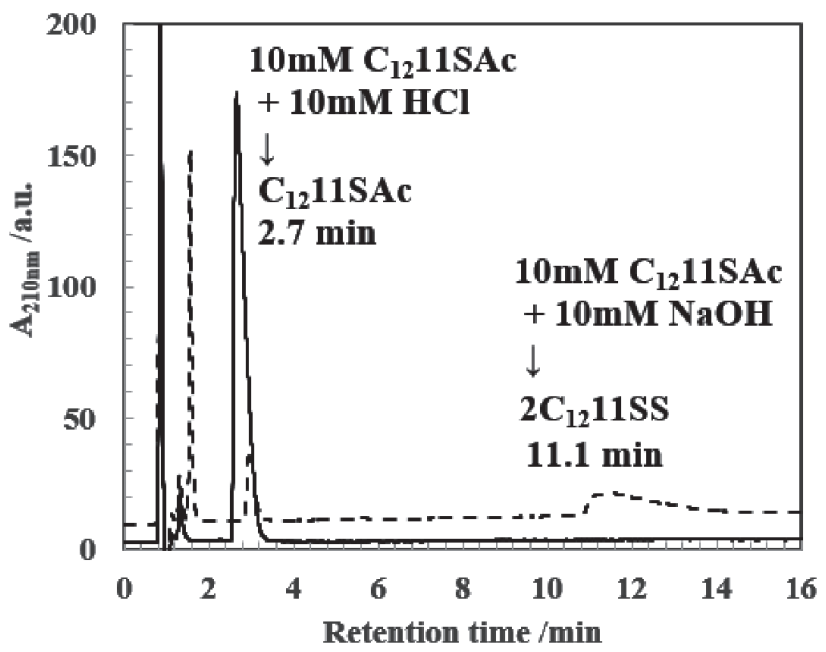

Fig. 3 HPLC analysis of $10 \mathrm{mM} \mathrm{C}_{12} 11 \mathrm{SAc}$ aqueous solution after the incubation for $24 \mathrm{~h}$ in $10 \mathrm{mM} \mathrm{HCl}$ at $40^{\circ} \mathrm{C}$, in comparison with the incubation in $10 \mathrm{mM} \mathrm{NaOH}$. The solid and broken lines were $\mathrm{C}_{12} 11 \mathrm{SAc}$ incubated in $\mathrm{HCl}$ and $\mathrm{NaOH}$, respectively.

The time course of the alkaline hydrolysis for the thioester surfactant is investigated by HPLC analysis ${ }^{23)}$. Figure 4 shows the chromatograms obtained using conductivity detector for $\mathrm{C}_{12} 4 \mathrm{SAc}$ systems. Aqueous solutions of $\mathrm{C}_{12} 4 \mathrm{SAc}$ $(10 \mathrm{mM})$ are incubated at $25^{\circ} \mathrm{C}$ in the presence of $10 \mathrm{mM}$ $\mathrm{NaOH}$. The elution of $\mathrm{C}_{12} 4 \mathrm{SAc}$ is detected at $1.7 \mathrm{~min}$, while that of $2 \mathrm{C}_{12} 4 \mathrm{SS}$ is seen at $3.0 \mathrm{~min}$ after incubation for 20 min. The peak area of $\mathrm{C}_{12} 4 \mathrm{SAc}$ decreases with time, while that of $2 \mathrm{C}_{12} 4 \mathrm{SS}$ increases. The $\mathrm{C}_{12} 4 \mathrm{SAc}$ in equimolar $\mathrm{NaOH}$ aqueous solution is converted into $2 \mathrm{C}_{12} 4 \mathrm{SS}$ by the hydrolysis and air oxidation for 4 days. $\mathrm{C}_{12} 4 \mathrm{SAc}$ and $\mathrm{C}_{12} 4 \mathrm{SH}$ peaks are not distinguished in the chromatograms, but the decrease in peak area at $1.7 \mathrm{~min}$ indicated the decrease in the total concentration of $\mathrm{C}_{12} 4 \mathrm{SAc}$ and $\mathrm{C}_{12} 4 \mathrm{SH}$.

The time-course of alkaline hydrolysis was examined by conductivity measurements. The consumption of hydroxide ions with hydrolysis would lead to a decrease in the conductivity of the aqueous solutions for the thioester surfactants. Figure 5 shows the time-course of the conductivity for $2 \mathrm{mM} \mathrm{C}_{12} \mathrm{nSAc}$ upon the addition of $2 \mathrm{mM} \mathrm{NaOH}$, in comparison with that for $2 \mathrm{mM}$ DDAB. The conductivities of the $2 \mathrm{mM}$ DDAB system increased rapidly with the addition of $\mathrm{NaOH}$. The behavior might be due to the presence of hydroxide ions, and the conductivity became almost constant within 2 min. A similar abrupt increase in conductivity also observed for $2 \mathrm{mM} \mathrm{C}_{12}$ nSAc systems with the addition of $\mathrm{NaOH}$, followed by an exponential decrease in conductivity with the progress of hydrolysis. The conductivities for the $\mathrm{C}_{12} 12 \mathrm{SAc}$ system reached a constant value within $60 \mathrm{~min}$. The hydrolysis rate for the $\mathrm{C}_{12} 12 \mathrm{SAc}$ system seemed to higher than that of the $\mathrm{C}_{12} 4 \mathrm{SAc}$ system. Under these experimental conditions, $\mathrm{C}_{12} 4 \mathrm{SAc}, \mathrm{C}_{12} 11 \mathrm{SAc}$, and

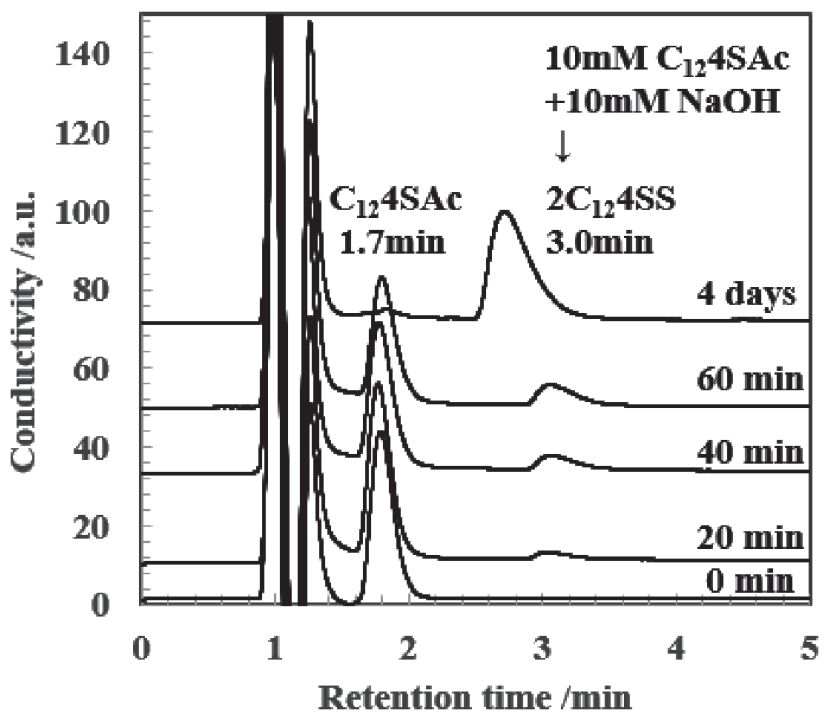

Fig. 4 HPLC analysis after 0, 20, 40, 60 min, and 4 days for $10 \mathrm{mM} \mathrm{C}_{12} 4 \mathrm{SAc}$ aqueous solution with the incubation in $10 \mathrm{mM} \mathrm{NaOH}$ at $25^{\circ} \mathrm{C}$.

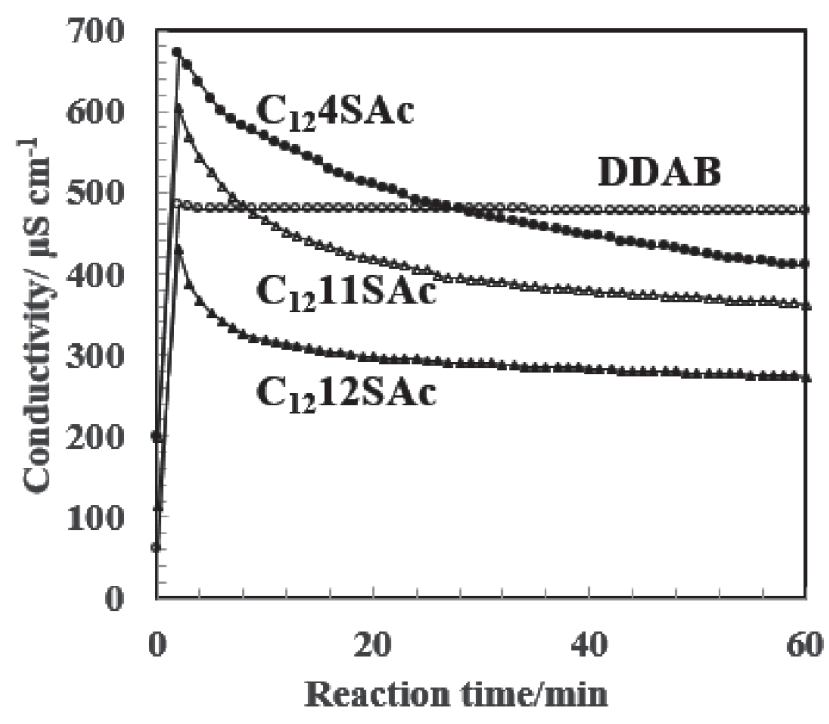

Fig. 5 The time-course of conductivity for $2 \mathrm{mM} \mathrm{C}_{12} \mathrm{nSAc}$ with addition of $2 \mathrm{mM} \mathrm{NaOH}$ in comparison with 2 mM DDAB. ( $\bigcirc) \operatorname{DDAB}_{(}\left(\mathrm{C}_{12} 4 \mathrm{SAc},(\triangle)\right.$ $\mathrm{C}_{12} 11 \mathrm{SAc},(\boldsymbol{\Delta}) \mathrm{C}_{12} 12 \mathrm{SAc}$.

$\mathrm{C}_{12} 12 \mathrm{SAc}$ will exist as monomers, micelles, and vesicles at a thioester surfactants concentration of $2 \mathrm{mM}$, respectively (Table 1). The concentration effect of the hydroxide ion could be anticipated from the cationic aggregates for the $\mathrm{C}_{12} 11 \mathrm{SAc}$ and $\mathrm{C}_{12} 12 \mathrm{SAc}$ systems.

Figure 6 shows the size distribution of the $\mathrm{C}_{12} 12 \mathrm{SAc}$ aggregates before and after incubation for 4 days in $4 \mathrm{mM}$ $\mathrm{NaOH}$ at $25^{\circ} \mathrm{C}$ in comparison with that for the DDAB vesicular systems. The $\mathrm{C}_{12} 11 \mathrm{SAc}$ and $\mathrm{C}_{12} 12 \mathrm{SAc}$ alkaline solutions gradually became an opaque blue color, indicating the remarkable growth of aggregates. HPLC analysis confirmed 


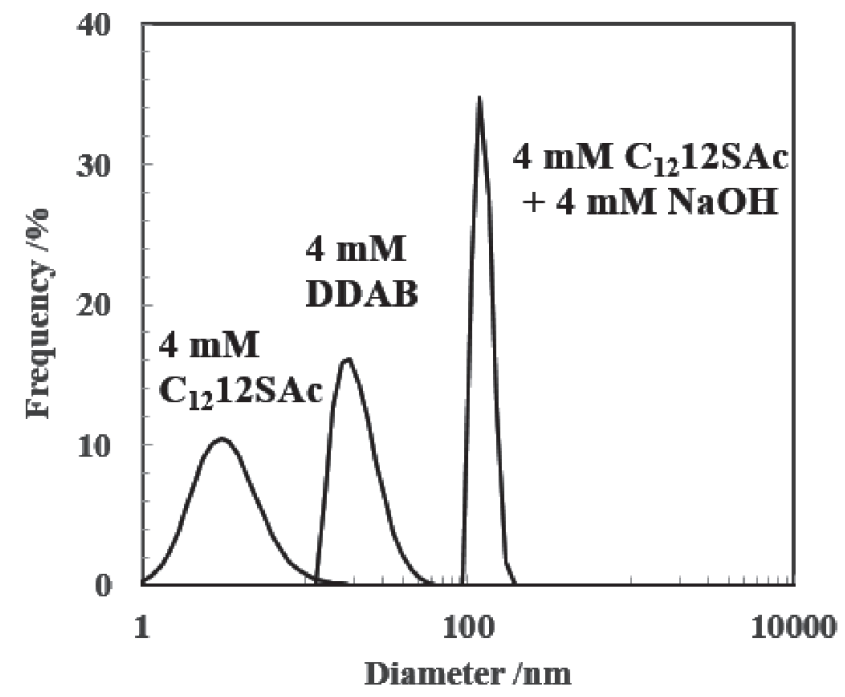

Fig. 6 The size distribution of $\mathrm{C}_{12} 12 \mathrm{SAc}$ aggregates before and after the incubation for 4 days in $4 \mathrm{mM} \mathrm{NaOH}$ at $25^{\circ} \mathrm{C}$ in comparison with DDAB vesicular systems.

the formation of a disulfide-linked surfactant, $2 \mathrm{C}_{12} 12 \mathrm{SS}$, and no peaks of $\mathrm{C}_{12} 12 \mathrm{SAc}$ and $\mathrm{C}_{12} 12 \mathrm{SH}$ were detected in the chromatogram. The hydrodynamic diameter of the $\mathrm{C}_{12}$ 12SAc vesicles was smaller than that of the DDAB vesicles, whereas the $2 \mathrm{C}_{12} 12 \mathrm{SS}$ system had significantly large vesicles, with sharper size distributions in comparison with those for DDAB. The average diameter of $2 \mathrm{C}_{12} 12 \mathrm{SS}$ and $2 \mathrm{C}_{12} 11 \mathrm{SS}$ vesicles were $123 \pm 11 \mathrm{~nm}$ and $58.8 \pm 2.6 \mathrm{~nm}$, respectively. The elimination of the polar thioester group induced an increase in vesicular size, abolishing the interdigitated packing in the vesicle bilayers. The disulfide linkage could contribute to the stability of vesicles, with disulfide bonds buried in the hydrophobic region, resulting in sharp size distributions of $2 \mathrm{C}_{12} 12 \mathrm{SS}$. The disulfide bonds can establish a link between the inner and outer layers and/or neighboring surfactants as illustrated in Scheme 2. The chemical structure of $2 \mathrm{C}_{12} 11 \mathrm{SS}$ was consistent with that of a disulfide-linked double tailed surfactant, similar to DDAB. The disulfide linkage between the double tailed surfactants is expected to contribute to the stabilization and growth of vesicles.

\section{CONCLUSION}

We succeeded in preparing double tailed surfactants having a thioester group in the terminal part of the second alkyl chain. The stimuli responsive surfactants, $\mathrm{C}_{12} \mathrm{nSAc}$, gave disulfide-linked gemini surfactants, $2 \mathrm{C}_{12} \mathrm{nSS}$, upon the alkaline hydrolysis and air oxidation. The experimental data suggested that the polar thioester group of $\mathrm{C}_{12} \mathrm{nSAc}(\mathrm{n}$ $=11,12$ ) could induce interdigitated packing in the vesicle bilayers, whereas the disulfide bonds buried in the hydrophobic region could contribute to the stability and growth of vesicles.

\section{ACKNOWLEDGMENT}

We would like to thank Editage (www.editage.jp) for English language editing.

\section{References}

1) Sakai, H.; Imamura H.; Kondo, Y.; Yoshino N.; Abe, M. Reversible control of vesicle formation using electrochemical reaction. Colloids Surf., A 232, 221-228 (2004).

2) Dong, J.; Xun, Z.; Zeng, Y.; Yu, T.; Han, Y.; Chen, J.; Li, Y.Y.; Yang, G.; Li, Y. Versatile and robust vesicle based on a photocleavable surfactant for two-photon-tuned release. Chem. Eur. J. 19, 7931-7936(2013).

3) Ghosh, S.; Dey, J. Interaction of sodium N-lauroylsarcosinate with $\mathrm{N}$-alkylpyridinium chloride surfactants: Spontaneous formation of $\mathrm{pH}$-responsive, stable vesicles in aqueous mixtures. J. Colloid Interface Sci. 358, 208-216 (2011).

4) Chung, M.-H.; Chung, Y.-C.; Chun, B.C. Highly pH-sensitive ion pair amphiphile vesicle. Colloids Surf., B 29, 75-80 (2003).

5) Castro, E.A. Kinetics and mechanisms of reactions of thiol, thiono, and dithio analogues of carboxylic esters with nucleophiles. Chem. Rev. 99, 3505-3524(1999).

6) Dong, J.; Xun, Z.; Zeng, Y.; Yu, T.; Han, Y.; Chen, J.; Li, Y.Y.; Yang, G.; Li, Y. Theoretical study on the alkaline hydrolysis of methyl thioacetate in aqueous solution. $J$. Phys. Chem. A 115, 13523-13533(2011).

7) Leclaire, J.; Vial, L.; Otto, S.; Sanders, J.K.M. Expanding diversity in dynamic combinatorial libraries: simultaneous exchange of disulfide and thioester linkages. Chem. Commun. 1959-1961 (2005).

8) Asakawa, T.; Shimizu, Y.; Ozawa, T.; Ohta, A.; Miyagishi, S. Aqueous solution properties of disulfide linked gemini and cleaved monomeric thiol surfactants. $J$. Oleo Sci. 57, 243-249(2008).

9) Kunitake, T.; Okahata, Y.; Tamaki, K.; Kumamaru, F.; Takayanagi, M. Formation of the bilayer membrane from a series of quaternary ammonium salts. Chem. Lett. 387-390 (1977).

10) Aratono, M.; Mori, A.; Koga, I.; Shigehisa, M.; Onimaru, N.; Tsuchiya, K.; Takiue, T.; Matsubara, H. Spontaneous vesicle formation of mixtures of double-chain cationic surfactants with a different counterion. J. Phys. Chem. B 112, 12304-12311 (2008).

11) Asakawa, T.; Ozawa, T.; Ohta, A. Generation of fluoro- 


\section{T. Asakawa, Y. Takano, A. Ohta et al.}

carbon and hydrocarbon hybrid gemini surfactants controlled by micellar miscibility. J. Oleo Sci. 62, 17-20(2013).

12) Hiramatsu, K.; Kameyama, K.; Ishiguro, R.; Mori, M.; Hayase, H. Properties of dilute aqueous solutions of double-chain surfactants, alkyldodecyldimethylammonium bromides with a change in the length of the alkyl chains. Bull. Chem. Soc. Jpn. 76, 1903-1910(2003).

13) Kawamura, H.; Manabe, M.; Nomura, M.; Inoue, T.; Murata, Y.; Sasaki, Y. Concentration-dependent change in aggregation states among monomer, micelles and vesicles observed in aqueous solution of didodecyldimethylammonium bromide. Nippon Kagaku Kaishi 10, 861-866 (1996).

14) Fujio, K.; Ozeki, S. Counterion binding to ionic surfactant micelles. J. Jpn Oil Chem. Soc. 49, 221-229 (2000).

15) Maeda T.; Satake, I. The micellar properties of dodecyltrimethylammonium chloride as studied by ion-selective electrodes and fluorescence probe method. Bull Chem. Soc. Jpn 61, 1933-1937 (1988).

16) Ingram, T.; Jones, M.N. Membrane potential studies on surfactant solutions. Trans Faraday Soc. 65, 297-304 (1968).

17) Rio, J.M.D.; Pombo, C.; Prieto, G.; Mosquera, V.; Sarmiento, F. Effect of temperature and alkyl chain length on the micellar properties of n-alkyltrimethyl- ammonium bromides in a low $\mathrm{pH}$ medium. J. Colloid Interface Sci. 172, 137-141 (1995).

18) Jansson, M.; Rymden, R. Counterion binding in aqueous solutions of mixed micellar aggregates from selfdiffusion measurements. J. Colloid Interface Sci. 119, 185-193 (1987).

19) Asakawa, T.; Kubode, H.; Ozawa, T.; Ohta, A.; Miyagishi, S. Micellar counterion binding probed by fluorescence quenching of 6-methoxy-N-(3-sulfopropyl) quinolinium. J. Oleo Sci. 54, 545-552(2005).

20) Viseu, M.I.; Velázquez, M.M.; Campos, C.S.; García-Mateos, I.; Costa, S.M.B. Structural transitions in a bicationic amphiphile system studied by light-scattering, conductivity, and surface tension measurements. Langmuir 16, 4882-4889 (2000).

21) Garcia, M.T.; Kaczerewska, O.; Ribosa I.; Brycki, B.; Materna, P.; Drgas, M. Hydrophilicity and flexibility of the spacer as critical parameters on the aggregation behavior of long alkyl chain cationic gemini surfactants in aqueous solution. J. Mol. Liq. 230, 453-460 (2017).

22) Fu, C.-W.; Lin, T.-H.; Theoretical study on the alkaline hydrolysis of methyl thioacetate in aqueous solution. $J$. Phys. Chem. A 115, 13523-13533(2011).

23) Luo, D.; Smith, S.W.; Anderson, B.D. Kinetics and mechanism of the reaction of cysteine and hydrogen peroxide in aqueous solution. J. Pharm. Sci. 94, 304316 (2005). 